\title{
Knowledge hoarding: antecedent or consequent of negative acts? The mediating role of trust and justice
}

Ann-Louise Holten, Gregory Robert Hancock, Roger Persson, Åse Marie Hansen and Annie Høgh

Ann-Louise Holten is based at Department of

Psychology, University of Copenhagen, Copenhagen,

Denmark.

Gregory Robert Hancock is based at Department of

Human Development and Quantitative Methodology,

University of Maryland, Washington, Maryland,

USA. Roger Persson is based at Department of Psychology, Lund University, Lund, Sweden. Ase Marie Hansen is based at Department of Public Health, University of

Copenhagen, Copenhagen, Denmark. Annie Høgh is based at Department of Psychology, University of Copenhagen, Copenhagen, Denmark.
Received 8 June 2015 Revised 22 October 2015 28 October 2015 Accepted 19 November 2015

(c) Holten, Hancock, Persson, Hansen, Høgh. Published by Emerald Group Publishing Limited. This article is published under the Creative Commons Attribution (CC BY 3.0) licence. Anyone may reproduce, distribute, translate and create derivative works of this article (for both commercial \& non-commercial purposes), subject to full attribution to the original publication and authors. The full terms of this licence may be seen at http://creativecommons.org/ licences/by/3.0/legalcode

\begin{abstract}
Purpose - The purpose of this paper is to investigate whether and how knowledge hoarding, functions as antecedent and consequent of work related negative acts, as a measure of bullying. The authors investigate the relation as mediated by trust and justice.

Design/methodology/approach - Data stem from a longitudinal study in which questionnaire responses were collected twice from 1,650 employees in 52 workplaces. Structural equation modelling was used to analyse the two models. Design-based corrections were made to accommodate the multi-level structure of data.

Findings - The analyses showed that knowledge hoarding was both an antecedent and a consequent of negative acts. First, over time, knowledge hoarding was indirectly related to negative acts mediated by trust and justice. Second, negative acts were both directly and indirectly related to knowledge hoarding over time. The study thus points to the existence of a vicious circle of negative acts, psychological states of trust and justice, and knowledge hoarding behaviours, which presumably will affect both individual and organizational outcomes negatively.

Research limitations/implications - The use of already collected, self-report data, single-item measures, and the two-year time lag could pose potential limitations to the study.

Practical implications - Preventive and repair actions could potentially impact both negative acts and knowledge hoarding by focusing on increasing the social exchange quality at work unit level.

Originality/value - This paper combines two strands of research, that of bullying at work and that of knowledge management, within which research on knowledge hoarding has been an under-researched area.
\end{abstract}

Keywords Justice, Trust, Structural equation modeling, Bullying, Knowledge hoarding,

Negative acts

Paper type Research paper

\section{Introduction}

Knowledge sharing, as a way to create, sustain, and transfer knowledge, has been found to affect individual (Quigley et al., 2007) and organizational performance (Hsu, 2008). In contrast to knowledge sharing, organizational behaviours of not sharing information have been defined by two constructs: knowledge hiding and knowledge hoarding. While knowledge hiding refers to a dyadic relationship between one individual requesting knowledge from another, who in response withholds that knowledge (Connelly et al., 2012), knowledge hoarding is defined as the simple withholding of knowledge, which has not been requested by any specific individual (Webster et al., 2008). As these two concepts target behaviours of knowledge withholding, it is reasonable to expect that they may demonstrate some degree of overlap. However, according to Connelly et al. (2012), the concepts are both theoretically and empirically distinguished. Theoretically, they differ on three main aspects: intentionality, request, and scope. Empirically, they are found to be 
weakly correlated and to demonstrate discriminant validity among their indicators. With regard to these discriminatory aspects, knowledge hoarding is thus defined by being a less intentional form of concealment, referring to knowledge not requested by specific others, and by having a smaller behavioural scope, than knowledge hiding (Connelly et al., 2012). Knowledge hoarding is particularly important, as it also captures elements of knowledge that are not necessarily explicit and understood by others (Evans et al., 2014). This type of knowledge may be impossible to request, yet essential for an organization to succeed.

Knowledge hoarding is a relatively new and under-researched topic in knowledge management research, which to a greater extent has focussed on knowledge sharing and more recently also on knowledge hiding (Connelly et al., 2012). While knowledge sharing may be interpreted as the positive side of knowledge management, knowledge hoarding is potentially associated with more negative organizational outcomes, such as deteriorated work-related interactions and diminished unit performance (Evans et al., 2014). Neither knowledge hiding nor knowledge hoarding is necessarily expressions of intentional, counterproductive behaviours, but may entail the risk of inducing them. Knowledge hiding behaviours may be understood as employees' attempt to avoid potential negative consequences of knowledge sharing, for example that knowledge sharing is time-consuming and holds a risk of losing individual power and status (Hislop, 2013). Although there is some research on reasons for engaging in knowledge hiding behaviours (expressed, for example, by evasive hiding, rationalized hiding, and playing dumb), little is known about their consequences (Connelly and Zweig, 2015), let alone about the antecedents, processes, and consequences of knowledge hoarding. With the purpose of adding to the developing stream of research in behaviours related to not sharing knowledge and combining that with the more established stream of research in bullying, the present paper specifically investigates whether and how knowledge hoarding, functions as antecedent and consequent of work related negative acts, as a measure of bullying behaviour.

The knowledge management literature holds various perspectives on what constitutes knowledge and whether and how it is distinct from information. It has both been suggested that information is a form of knowledge and that information and knowledge are distinct entities. When the two are distinguished, knowledge is often presented as the more complex and valuable (Stenmark, 2002). The usage of the concepts of information and knowledge overlap both in common usage and specialized fields (Meadow and Yuan, 1997). This is also true in the knowledge management literature (Connelly et al., 2012; Peng, 2012). Consequently, the present study does not distinguish explicitly between information and knowledge, but focus instead on the non-sharing behaviours of employees.

\section{Knowledge hoarding and negative acts}

The concept of negative acts at work targets a range of unwanted behaviours, which, when combined and experienced over time, may define workplace bullying (Nielsen et al., 2011). The present study applies a conceptualization of bullying corresponding to the following definition:

Bullying at work means harassing, offending, or socially excluding someone or negatively affecting someone's work. In order for the label bullying (or mobbing) to be applied to a particular activity, interaction, or process, the bullying behaviour has to occur repeatedly and regularly (e.g., weekly) and over a period of time (e.g., about six months). (Einarsen et al., 2011, p. 22).

Experiencing negative acts at work may have both individual and organizational consequences. Two reviews provide examples of such consequences at the individual level in terms of anxiety, cardiovascular diseases, depressed mood, and depression (Hogh et al., 2011) and at the organizational level in terms of higher turnover, absenteeism, and reduced productivity (Hoel et al., 2011). As there are indications that knowledge hoarding can be associated with the quality of work-related interactions (Evans et al., 2014) and that 
hiding and hoarding behaviours are separate from counterproductive workplace behaviours (Connelly et al., 2012), it seems warranted to increase the knowledge and awareness of the relation between knowledge hoarding and negative acts. For this purpose, the present study applies the theoretical framing of the social exchange theory (Homans, 1961), according to which the history and quality of interpersonal interactions set the scene for future interactions. Two expressions of the quality of such interpersonal interactions are the psychological states of trust and justice. As these states have shown to be important for the interactions and effective performance of organizational members (Colquitt et al., 2007, 2012), they are integrated as potential mediators in the present study.

The longitudinal design of the present study allows for the analysis of both causal relations and organizational processes. By extension, the reciprocal causality hypothesis of the relation between knowledge hoarding and negative acts is tested, investigating both direct and indirect (mediated by trust and justice) mechanisms. The models studied thus integrate three categories of phenomena: the behaviours of knowledge hoarding, the psychological states of trust and justice, and the events of negative acts. These phenomena are studied at two levels: at the individual level tapping into each employees' experience of negative acts and at work unit level tapping into knowledge hoarding, trust, and organizational justice in a more generalized form. The choice to measure concepts at either individual or work unit level reflects the targeting of measures towards individual experiences and collective relations and behaviours, respectively. The two levels are reflected in the measures applied to investigate the study hypotheses.

\subsection{Negative acts as outcomes of knowledge hoarding}

Social exchange theory suggests that individuals act out of self-interest, which is regulated by rewards (Homans, 1961) and cost-benefit calculations (Blau, 1964). Applied to the field of knowledge management, self-interest is indeed a potential motive for individuals not to share knowledge. Such behaviours could for example relate to the intention of enhancing one's individual bargaining power and influence in the workplace (Evans et al., 2014). However, if knowledge hoarding is perceived and interpreted by colleagues as self-serving and uncooperative, such behaviour risks being reciprocated by negative and counterproductive actions. Opportunistic behaviours are indeed often followed by social sanctions in terms of marginalization and withdrawal of respect by colleagues (Dyer and $\mathrm{Chu}, 2000)$. Therefore, perceived knowledge hoarding may lead to difficult relationships between colleagues (Evans et al., 2014; Szulanski, 1996). Following, the present study hypothesizes that over time, the occurrence of negative acts is an outcome of perceived knowledge hoarding (Figure 1):

\section{Figure 1 Model 1 - Knowledge hoarding and negative acts}

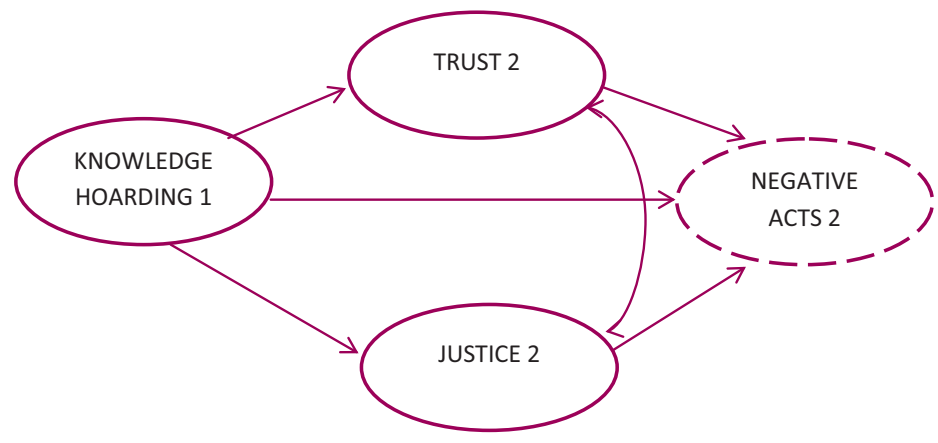

Note: Broken line: individual level; full line: work unit level 
H1. Knowledge hoarding will be positively related to negative acts.

Investigating the mechanisms through which knowledge hoarding may lead to negative acts, the model integrates trust and justice. Trust has been defined as a psychological state in which one accepts being vulnerable in positive expectation of the intentions and actions of another person (Rousseau et al., 1998). Well-known measures of trust have, for example, targeted specific relations between managers (cognition- and affect-based trust), between individuals working across organizations, between collective entities (for example departments), and across vertical relations (McEvily and Tortoriello, 2011). For the present study, the intention is not to estimate the specific individual characteristics of either the trustee or the trustor and thereby measure trust at the individual level, nor to estimate the quality of a certain dyadic relation either between individuals or departments/organizations. Instead, trust is studied at work unit level, targeting the perceived degree of trust present between employees in general. Thus, the construct reflects a behaviourally based trust dimension of horizontal trust. Within a trust process perspective, this study therefore focuses on the trust output (behaviours) and not the phases of trust input (individual characteristics and motives or situational and organizational constraints) or trust process (trust belief and decision) (Dietz and Den Hartog, 2006).

Being an inherently positive concept, much trust research has indeed focussed on positives. It has for example been found that trust enhances positive behaviours, such as extra-role performance and organizational citizenship behaviours (Searle et al., 2011). In contrast, research investigating negative elements of trust relates mainly to breach of trust and distrust. Although being inspired by research on distrust, the present study focuses on the concept of trust, which is distinct in nature from and with different psychological underpinnings than distrust (McKnight et al., 2004). Thus inspired by Černe et al. (2014), who found that knowledge hiding causes distrust, the present study proposes that when employees perceive knowledge hoarding, potentially interpreting them as expressions of being self-enhancing and uncooperative, their positive expectations of the intentions and actions of others, which are inherent to trust, could be affected. Further, while trust makes organizations more efficient through supporting the social exchange mechanisms (Bijlsma and Koopman, 2003), lack of trust may do the opposite or, as it has been shown, even lead to counterproductive behaviours (Bies and Tripp, 1996) such as negative acts.

Organizational justice has been defined as the subjective perception of fairness in three main forms: procedural, distributional, and interactional. The present study applies the entity conceptualization of justice (Colquitt et al., 2013), which has been recommended for predictive studies (Hauenstein et al., 2001). The majority of justice studies have investigated its relation to outcomes, resulting in limited knowledge of justice antecedents (Cohen-Charash and Spector, 2001). Conceptualizing knowledge as a resource (Alavi and Leidner, 2001), knowledge hoarding behaviours impair employees' equal access to that resource, which may influence the experienced justice at work. Within this knowledge-resource frame, knowledge hoarding may thus be an antecedent factor to employees' justice perception. Justice has understandably been studied in relation to outcomes such as commitment and job satisfaction (Lambert et al., 2007), but justice has also been found to relate negatively to workplace aggression (Jawahar, 2002; St-Pierre and Holmes, 2010) and counterproductive work behaviours (Cohen-Charash and Spector, 2001; Colquitt et al., 2013). Specifically with regard to bullying, Tepper (2000) found that injustice mediates the relation between bullying and anxiety and emotional exhaustion. In light of this, the present study hypothesizes that trust and justice will mediate the relation between knowledge hoarding and negative acts:

H2. Knowledge hoarding will be positively related to negative acts, mediated by both trust and justice. 
Because research in knowledge hoarding is scarce, and it seems plausible that being subjected to negative acts may also impact whether and how knowledge is shared, the present study tests the reverse causality hypothesis suggesting that negative acts contribute to knowledge hoarding (Figure 2). In bullying research, calls have been made for studies on how bullying may lead to the questioning of social norms, which guide the social relations at work (Parzefall and Salin, 2010). This is relevant to the present study, as the nature of social exchanges has been proposed as an antecedent of knowledge hoarding (Webster et al., 2008). Indeed, perceived negative acts may result in employees experiencing a low quality of social exchange relations at work (Robinson, 2008), expressed, for example, as difficulties in knowledge transfer between source and recipient (Szulanski, 1996). It is thus hypothesized that negative acts will contribute to knowledge hoarding over time:

H3. Negative acts will be positively related to knowledge hoarding.

According to international employment acts (for example, the European Framework Directive on Safety and Health at Work; Directive 89/391 EEC), workplaces should be safe and secure for their employees. A safe and secure workplace potentially constitutes an important element of the psychological contract, which is defined as beliefs about reciprocal obligations between an employee and his/her organization (Morrison and Robinson, 1997). Failing to meet such obligations constitutes psychological contract breach, which relates to reduced trust (Robinson, 1996). While, on the one hand, trust has been found to enhance knowledge sharing behaviours (Dirks and Ferrin, 2001; Ismail Al-Alawi et al., 2007; Jarvenpaa and Majchrzak, 2008; Renzl, 2008), on the other hand, employees are more likely to hide knowledge from colleagues whom they distrust (Connelly et al., 2012). Being exposed to workplace bullying may thus be interpreted as a breach to the psychological contract and therefore associated with knowledge hoarding behaviours through reduced trust.

The experience of bullying has also shown to have negative effects on basic world assumptions, such as justice (Mikkelsen and Einarsen, 2002). However, the relation between bullying and injustice has been suggested to be both consequential and simultaneous in nature (Parzefall and Salin, 2010). Less is known about the relation between justice and behaviours of not sharing information; therefore, specific calls for research on justice and knowledge hiding have been made within the knowledge management literature (Connelly et al., 2012). Through the concept of equitable relationships, described by Walster et al. (1973), it is proposed that individuals have a tendency to restore equity to eliminate the distress following experienced inequity. Strategies to restore equity could either be attempted through actual compensation (for example, through acts to increase the other person's outcome) or psychological

\section{Figure 2 Model 2 - Negative acts and knowledge hoarding}

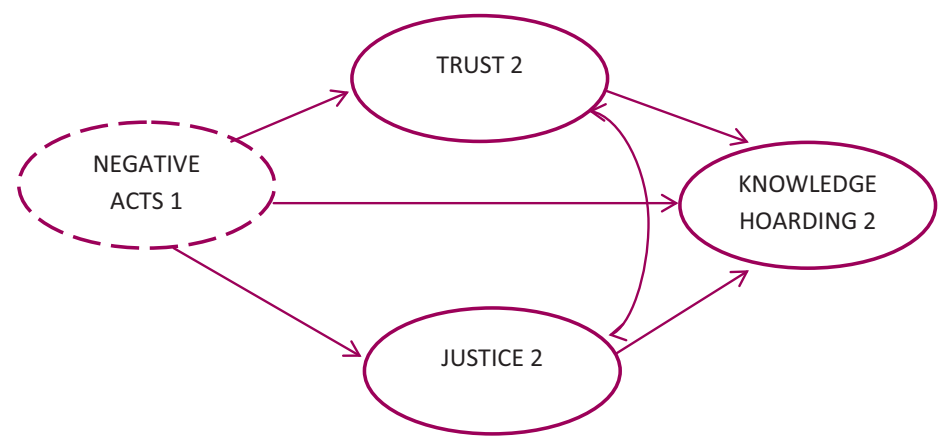

Note: Broken line: individual level; full line: work unit level 
rationalization (for example, through denying one's own responsibility). Applied to the field of justice, when injustice is experienced, employees will try to re-establish a balanced social exchange situation either by re-establishing justice as such or by creating a sense of psychological justice. Behaviours of not sharing information could be a potential way to re-establish such a sense of social exchange balance for the individual. It has specifically been suggested that the experience of unfair decision-making processes can lead to knowledge hoarding (Kim and Mauborgne, 1998). With the purpose of re-establishing balance and psychological justice, knowledge hoarding could therefore be a potential behavioural response to experienced low or reduced justice. It is consequently hypothesized that the relation between negative acts and knowledge hoarding will be mediated by trust and justice:

H4. Negative acts will be positively related to knowledge hoarding, mediated by both trust and justice.

\section{Methodology}

\subsection{Study design and data collection}

Questionnaires were administered twice (at T1 in 2006 and at T2 in 2008) to employees in 52 workplaces (30 public and 22 private) with 1,664 employees responding at both times (Hansen et al., 2011). The type of workplaces ranged from schools, hospitals, and public administration, to construction, finance, and transport. Response rates were 46 (T1) and 49.5 per cent (T2). Due to missing work unit information, the final longitudinal sample for analysis contained 1,650 respondents distributed across 295 work units. Work unit size ranged from one to 77 employees, with a mean of six employees per unit.

\subsection{Measures}

In contrast to knowledge hiding, which has mainly been investigated as an individual level construct (Connelly et al., 2012), the present study investigates knowledge hoarding at the group level, pointing towards a more generalized perception of employees withholding information from each other. Further, the construct is investigated at an overall level, targeting the specific behaviours of knowledge hoarding, not the reasons or strategies for doing so. Focus is thereby on the perceived hoarding of employees in general and not individual, self-reported hoarding behaviours. This is an approach that has only recently been applied in relation to individual and unit outcomes (Evans et al., 2014).

With regard to level and referent, the measures applied in the present study are aligned with its hypotheses and data analyses. Knowledge hoarding, trust, and justice are therefore investigated at work unit level and negative acts at individual level. The work unit level measures are referent aligned such that knowledge hoarding and trust refer to a measure of behaviours, which can be generally observed between employees and therefore has a neutral, generalized referent. The justice construct refers to generalized perceptions of procedural, distributional, and interactional justice with general management as the implicit referent. Negative acts refer to the individual level of experiencing such events with a neutral referent.

Knowledge hoarding at $\mathrm{T} 1(\mathrm{KH} 1)$ and $\mathrm{T} 2(\mathrm{KH} 2)$ were measured by one item targeting the occurrence of information withholding among employees ("Do employees withhold information from each other?"); response categories ranged from 1 ("To a very high degree") to 5 ("To a very low degree").

Negative acts at T1 (NA1) and T2 (NA2) were measured by two scales: person-related and work-related acts. Negative acts (person-related) (with Cronbach internal consistency reliability of $\alpha_{\mathrm{T} 1}=0.86, \alpha_{\mathrm{T} 2}=0.85$ ) were measured by 12 items (Einarsen et al., 2009) ("How often have you been exposed to the following act within the past 6 months? Spreading of gossip and rumours about you."); response categories ranged from 1 ("Never") to 5 ("Daily"). This measure targets the experience of being humiliated, teased, criticized, insulted, ignored, excluded, and repeatedly reminded of errors. Negative acts (work-related) $\left(\alpha_{\mathrm{T} 1}=0.74, \alpha_{\mathrm{T} 2}=0.74\right)$ were measured by seven items (Einarsen et al., 
2009) ("How often have you been exposed to the following act within the past 6 months? Being ordered to do work below your level of competence."); response categories ranged from 1 ("Never") to 5 ("Daily"). This measure targets the experience of being given tasks with unreasonable deadlines or below one's level of competence, excessive monitoring of one's work, having one's opinions ignored, and one's performance is being affected by someone withholding information.

Trust at T1 (TR1) and T2 (TR2) were measured by one item targeting horizontal trust ("Do employees trust each other in general?"); response categories ranged from 1 ("To a very high degree") to 5 ("To a very low degree").

Justice at T1 (JU1) and T2 (JU2) $\left(\alpha_{\mathrm{T} 1}=0.82, \alpha_{\mathrm{T} 2}=0.82\right)$ were measured by three items targeting procedural ("Is one treated fairly?"), distributional ("Is the work distributed fairly?"), and interactional justice ("Are conflicts solved in a just way?"); response categories ranged from 1 ("To a very high degree") to 5 ("To a very low degree").

All measured variables were scaled or reversed such that larger numbers indicated greater amounts of the variable of interest.

\subsection{Data analysis}

Emphasizing the contextual nature of social relations, the concepts of trust, justice, and knowledge hoarding were analysed at work unit level. Such a work unit-level approach has been suggested for justice - but not yet for trust (Lavelle et al., 2007) and knowledge hoarding. The Mplus software (version 7) was used for all analyses.

Two structural equation models were analysed, information for which is shown in Figures 1 and 2 (note that factors are shown without their measured indicator variables). Model 1 tested the causal relation between knowledge hoarding at T1 and negative acts at T2, mediated by trust and justice (both at T2). Model 2 tested the causal relation between negative acts at $\mathrm{T} 1$ and knowledge hoarding at $\mathrm{T} 2$, mediated by trust and justice (both at T1). Models were fitted using full information maximum likelihood estimation to accommodate missing data, with robust corrections to test statistics and standard errors to adjust for potential non-normality in the data and using bootstrapping to test each model's indirect effects. The multi-level structure of the data was also taken into account to make the necessary design-based corrections to the resulting model output (Stapleton, 2013). Finally, model fit was assessed using an absolute fit index (standardized root mean square residual), a parsimonious fit index (root mean square error of approximation), and an incremental fit index (comparative fit index).

\section{Results}

Means, standard deviations, and correlations appear in Table I. Except for the relations between NA1 and $\mathrm{JU} 2$ and between $\mathrm{NA} 2$ and $\mathrm{KH} 1$, all measures were statistically significantly correlated $(p<0.05)$. Note that these preliminary descriptive statistics were not adjusted for the multi-level data structure.

Data-model fit statistics are presented in Table II. Both models show acceptable fit. The resulting standardized parameter estimates for $\mathrm{H}_{1}$ and $\mathrm{H} 2$ are listed in Table III and illustrated in Figure 1. Revealing a non-significant direct effect (DE) between knowledge hoarding and negative acts ( $\mathrm{DE}=0.047, p=0.135$ ), Model 1 did not support $H 1$. The standardized path coefficient was negative and statistically significant between knowledge hoarding and trust $(\mathrm{DE}=-0.322)$ and between knowledge hoarding and justice (DE = $-0.253)$, as was the standardized path coefficient between justice and negative acts $(D E=-0.310)$. The relation between trust and negative acts was negative and non-significant ( $\mathrm{DE}=-0.051, p=0.289$ ). The standardized indirect effect (IE) mediated by trust was a non-significant $\mathrm{IE}=(-0.322)(-0.051)=0.016$, whereas the standardized $\mathrm{IE}$ mediated by justice was a statistically significant IE $=(-0.253)(-0.310)=0.078$. H2 was thus supported for justice, but not for trust. 
Table I Means, standard deviations, and correlations for model measures

\begin{tabular}{|c|c|c|c|c|c|c|c|c|c|}
\hline Composites & $M$ & $(S D)$ & 1 & 2 & 3 & 4 & 5 & 6 & 7 \\
\hline 1. NA1 & 1.3 & 0.33 & 1 & & & & & & \\
\hline 2. NA2 & 1.3 & 0.31 & $0.52^{\star \star}$ & 1 & & & & & \\
\hline 3. TR1 & 3.7 & 0.70 & $-0.36^{\star *}$ & $-0.22^{\star *}$ & 1 & & & & \\
\hline 4. TR2 & 3.7 & 0.68 & $-0.05^{\star}$ & $-0.23^{\star *}$ & $0.11^{\star \star}$ & 1 & & & \\
\hline 5. JU1 & 3.3 & 0.69 & $-0.50^{* *}$ & $-0.35^{\star *}$ & $0.52^{\star \star}$ & $0.10^{* *}$ & 1 & & \\
\hline 6. JU2 & 3.3 & 0.69 & -0.04 & $-0.18^{\star *}$ & $0.09 * *$ & $0.58^{\star *}$ & $0.16^{\star *}$ & 1 & \\
\hline 7. $\mathrm{KH} 1$ & 2.2 & 0.91 & $0.09^{\star \star}$ & 0.05 & $-0.13^{\star \star}$ & $-0.29^{\star \star}$ & $-0.11^{\star *}$ & $-0.28^{\star \star}$ & 1 \\
\hline 8. $\mathrm{KH} 2$ & 2.2 & 0.91 & $0.28^{\star \star}$ & $0.41^{\text {** }}$ & $-0.30^{\star \star}$ & $-0.17^{\star \star}$ & $-0.30^{\star \star}$ & $-0.16^{\star \star}$ & $0.13^{\star \star}$ \\
\hline
\end{tabular}

Notes: ${ }^{\star *} p<0.01 ;{ }^{\star} p<0.05 ; N=1303-1598$; all composites are measured on a 1-5-point scale; higher scores indicate higher levels

\section{Table II Fit indices for Models 1 and 2}

\begin{tabular}{ccccccr} 
Models & $x^{2}$ & $d f$ & $p$ & SRMR & RMSEA & CFI \\
\hline Model 1 & 15.43 & 10 & 0.117 & 0.016 & 0.018 & 0.996 \\
Model 2 & 27.38 & 10 & 0.002 & 0.026 & 0.032 & 0.982
\end{tabular}

Notes: $\varkappa^{2}=$ model chi-square; $d f=$ degrees of freedom; SRMR = standardized root mean square residual; RMSEA = root mean square error of approximation; CFI = comparative fit index

\section{Table III Standardized direct and indirect effects for Models 1 and 2}

\begin{tabular}{|c|c|c|c|}
\hline Path(s) & Effect estimate & S.E. & $\mathrm{p}$ \\
\hline \multicolumn{4}{|l|}{ Model 1} \\
\hline $\mathrm{KH} 1 \rightarrow \mathrm{TR} 2$ & -0.322 & 0.058 & $<0.001$ \\
\hline $\mathrm{KH} 1 \rightarrow \mathrm{JU} 2$ & -0.253 & 0.076 & 0.001 \\
\hline $\mathrm{KH} 1 \rightarrow \mathrm{NA} 2$ & 0.047 & 0.031 & 0.135 \\
\hline TR2 $\rightarrow$ NA2 & -0.051 & 0.048 & 0.289 \\
\hline JU2 $\rightarrow$ NA2 & -0.310 & 0.055 & $<0.001$ \\
\hline $\mathrm{KH} 1 \rightarrow \mathrm{TR} 2 \rightarrow \mathrm{NA} 2$ & 0.016 & - & $>0.10$ \\
\hline $\mathrm{KH} 1 \rightarrow \mathrm{JU} 2 \rightarrow \mathrm{NA} 2$ & 0.078 & - & $<0.01$ \\
\hline \multicolumn{4}{|l|}{ Model 2} \\
\hline $\mathrm{NA} 1 \rightarrow \mathrm{TR} 1$ & -0.269 & 0.040 & $<0.001$ \\
\hline NA1 $\rightarrow$ JU1 & -0.332 & 0.038 & $<0.001$ \\
\hline $\mathrm{NA} 1 \rightarrow \mathrm{KH} 2$ & 0.084 & 0.030 & $<0.01$ \\
\hline $\mathrm{TR} 1 \rightarrow \mathrm{KH} 2$ & -0.293 & 0.058 & $<0.001$ \\
\hline $\mathrm{JU} 1 \rightarrow \mathrm{KH} 2$ & -0.197 & 0.065 & $<0.01$ \\
\hline $\mathrm{NA} 1 \rightarrow \mathrm{TR} 1 \rightarrow \mathrm{KH} 2$ & 0.079 & - & $<0.01$ \\
\hline $\mathrm{NA} 1 \rightarrow \mathrm{JU} 1 \rightarrow \mathrm{KH} 2$ & 0.065 & - & $<0.01$ \\
\hline
\end{tabular}

Notes: Indirect effects were tested using bootstrapping, for which standard errors were not available; $\mathrm{KH} 1 / \mathrm{KH} 2=$ Knowledge hoarding Time 1 and Time 2; TR1/TR2 = Trust Time 1 and Time 2; NA1/NA2 = Negative Acts Time 1 and Time 2; JU1/JU2 = Justice Time 1 and Time 2

The standardized parameter estimates for $\mathrm{H3}$ and $\mathrm{H} 4$ are listed in Table III and illustrated in Figure 2. In support of $H 3$, Model 2 revealed a statistically significant positive DE between negative acts and knowledge hoarding ( $D E=0.084, p<0.01$ ). The standardized path coefficient was negative and statistically significant between negative acts and trust at $(\mathrm{DE}=-0.269, p<0.001)$ and between negative acts and justice at $(\mathrm{DE}=-0.332, p<0.001)$. Similarly, the standardized path coefficients were negative and statistically significant between trust and knowledge hoarding ( $\mathrm{DE}=$ $-0.293, p<0.001)$ and between justice and knowledge hoarding ( $D E=-0.197, p<$ $0.01)$. H4 was thus supported. The standardized IE mediated by trust was a statistically significant IE $=(-0.269)(-0.293)=0.079$ and by justice a statistically significant IE $=$ $(-0.332)(-0.197)=0.065$. 


\section{Discussion}

The main motivation for the development of knowledge management research has been the critical importance of the creation and transfer of knowledge for organizational success (Zhang, 2009). To date, little is known about the behaviours of not sharing information, which is currently receiving increased research interest. Research on knowledge hiding has however shown that such behaviours occur regularly (Connelly et al., 2012) and have potential negative outcomes (Černe et al., 2014; Connelly and Zweig, 2015). Even less is known about antecedents and consequences of the specific behaviours of knowledge hoarding.

The present study points to the existence of a vicious circle of negative acts, psychological states of trust and justice, and knowledge hoarding behaviours, which presumably will affect both individual and organizational outcomes negatively. Knowledge, of the specific processes of how, why, and when knowledge hoarding behaviours transpire, is essential for understanding how to prevent and repair such behaviours. The present study contributes specifically to knowledge of the knowledge hoarding processes and does not explore the reasons or strategies for behaviours of not sharing knowledge.

As hypothesized, knowledge hoarding did predict negative acts over time. This relation was however not a direct one - but instead it was mediated by justice. At the individual level, the relation between knowledge hoarding and negative acts could reflect a reciprocation mechanism through which behaviours of not sharing knowledge could be perceived as self-serving and opportunistic conducts, which would potentially be reciprocated by social sanctions in the form of negative acts. The construct of knowledge hoarding, however, is non-dyadic and refers to non-sharing behaviours which are not directed towards one particular individual. Interpreting the relation between knowledge hoarding and negative acts at the work-unit level instead, knowledge hoarding represents potential self-interest among employees more generally, resulting in unequal access to workplace resources. This interpretation illustrates the indirect mechanism through which knowledge hoarding leads to negative acts through a reduced degree of justice.

The finding of reciprocal causality, that negative acts predict knowledge hoarding over time - directly and through reduced trust and justice, also offers a perspective on reasons for hoarding behaviours. It seems that a non-cooperative and even hostile environment could produce reasons for hoarding, either in the form of self-protection or as individual or collective retaliation. This may indeed be an illustration of how bullying may lead to the questioning of the social norms at work - for example, through a psychological breach mechanism (reduced trust) and/or negatively affected basic world assumptions (reduced justice). The enactment of negative acts would thus express a response to contract breach, by non-compliance and/or attempting to restore equitable relationships and re-establishing justice. Further, if that is indeed the case, a cooperative and friendly environment could potentially reduce behaviours of knowledge hoarding and possibly even contribute to knowledge sharing.

The identified effects in the present study occur over a period of two years, implying that the negative, reciprocal impact of knowledge hoarding and negative acts are both severe and persistent. One should therefore not only be concerned with the immediate outcomes of knowledge hoarding and negative acts but indeed also be aware that these phenomena are interrelated and affect each other over time, thus potentially adding to their separate negative organizational outcomes.

The fact that the present study shows important relations between knowledge hoarding, as a work unit construct, and negative acts experienced at the individual level is important, both methodologically and theoretically. Methodologically, the study demonstrates the importance of investigating organizational phenomena across levels. Theoretically, the study shows how the nature of constructs implicitly suggests different levels of measurement. In contrast to the current definition of knowledge hiding, knowledge

\begin{tabular}{l|l|l} 
VOL. 20 NO. 22016 & JOURNAL OF KNOWLEDGE MANAGEMENT & PAGE 223
\end{tabular} 
hoarding does not occur within a dyadic interpersonal relationship. The present study finds that knowledge hoarding, as occurring at work unit level, with no evident source and recipient, affects both the degree to which employees experience work unit level horizontal trust and organizational justice. Further, justice is a significant mediator of the relation between knowledge hoarding and negative acts. This illustrates that experiencing knowledge withholding behaviours, which are not necessarily directed at oneself personally, but instead as a more general behaviour within a work unit, is a significant predictor of negative outcomes - for the organization as well as the individuals within them.

\section{Conclusion}

The findings of the present study demonstrate that knowledge hoarding among employees is causally related to the experience of less trust and justice over time, suggesting that knowledge hoarding is a factor of concern when it comes to understanding the deterioration of the quality of social exchange at work. Knowledge hoarding does not appear to cause a direct change in the degree to which work-related negative acts are experienced. Instead, the effect of knowledge hoarding on negative acts is indirect, denoting that the reduced justice experience, caused by knowledge hoarding, is associated with increased reports of work-related negative acts. In other words, when employees withhold information from each other, it has a long-term, negative impact on the degree to which they trust each other and feel that the workplace treats them fairly. The experience of fair treatment is per se associated with the degree to which employees report to experience negative acts. The study thus gives evidence of a variety of negative consequences of knowledge hoarding.

Testing the reverse causality hypothesis, the study documents a direct causal relation between negative acts and knowledge hoarding. This suggests that the experience of negative acts may over time produce a general culture or norm of hoarding knowledge among employees. The study further demonstrates that this relation is mediated by both trust and justice. The interpretation offered in the present paper of the experience of negative acts representing psychological contract breach elucidates the associated state of reduced trust and justice, leading to an increase of knowledge hoarding behaviours over time. Knowledge hoarding is thus important both as antecedent and consequent of negative acts.

Although the present study has successfully demonstrated both antecedents and consequences of knowledge hoarding, it also holds certain limitations. First, the study applies a data set already gathered to test the study hypotheses. While this has the obvious limitation of having less influence over the exact study design, there are essential reasons for applying this particular data set - most importantly, that it covers a variety of sectors and a large number of workplaces. While extremely valuable, workplace data are at the same time very laborious and difficult to access in large scale.

Second, as a consequence of the above, the study was restricted to applying two single-item measures, which do not afford the benefit of disattenuating their structural connections to other key model variables of the effects of measurement error. That is, the structural effects associated with trust and knowledge hoarding, estimated in this study, would be expected to be conservative; had multiple indicator measures been available, more reliable information would have allowed for even stronger path estimates associated with trust and knowledge hoarding. That said, most of the effects involving these variables were nonetheless found to be statistically significant.

Third, because all of the applied measures stem from one self-report data source, it cannot be ruled out that some degree of common method bias operates on the data (Podsakoff et al., 2003). Potentially compensating for this limitation, all measures (except for negative acts) relate to different measurement levels and referents beyond the self. Fourth, the data were longitudinal with a measurement time lag of two years. While these data allow taking 
a first step towards understanding causal relations of both antecedents and consequents of knowledge hoarding, it could be argued that either shorter or longer follow-up time lags would provide information on either more proximal or distal effects.

The findings of the present study suggest various avenues for practice. By focusing on increasing the social exchange quality at work unit level, preventative and repair actions could have bearing on both knowledge hoarding and negative acts. From a preventative perspective, the causal relation between negative acts and knowledge hoarding constitutes an important dual potential for anti-bullying activities. Such activities would not only have the benefit of preventing the occurrence of negative acts but also consequently knowledge hoarding behaviours. Therefore, attempts to decrease the occurrence of knowledge hoarding could be both direct, aiming directly at the knowledge management strategies of a given organization, and indirect as a positive side-effect to preventively targeting the occurrence of negative acts at work. Typical company actions targeted towards the counteracting of bullying are written anti-bullying policies, surveys, training, and information (Salin, 2008). Such actions to reduce bullying may however not be the most efficient. A recent review on interventions to prevent workplace bullying and incivility shows that many anti-bullying initiatives are based on the assumption that bullying will decrease if managers and employees have knowledge about the phenomenon and if they become more assertive in their response to it (Hodgins et al., 2014). Instead, what seems to be successful for the prevention of bullying relates to the application of overall principles for organizational interventions: participation, responsiveness, contextual embeddedness, and empowerment (Hodgins et al., 2014). In such interventions, it is also important to take the implementation process and evaluation into account (Vartia and Leka, 2011).

The models of the present study also suggest an alternative preventative approach, which would be to ensure a work environment that supports high levels of trust and justice. Both overall leadership strategies and specific managerial actions to develop and support such high-quality social exchange relations could therefore be recommended. From a general perspective, it has been found that transformational leadership (through communicating a vision and shared values and involving employees in decision-making) increases the trust in management (Gillespie and Mann, 2004). From a more specific perspective, four organizational policies have been identified, which may stimulate such interpersonal trust building. These four policies target the creation of a relationship-oriented culture, the facilitation of relational signalling among employees, the explicit socialization of newcomers, and the management of employee competencies (Six and Sorge, 2008). The managerial actions reflecting these policies, promoted in the study by Six and Sorge (2008), are, for example, to facilitate that colleagues meet informally to exchange relational signals and to apply planning procedures to match individual employees' competencies and tasks.

Taking it to the organizational level, actions to prevent bullying should be aimed at developing the organization generally. Organizational development does indeed focus on enabling a change in organizational culture, attitudes, values, and beliefs, which emphasize and support healthy processes and interpersonal relations at work (Hodgins et al., 2014). Leadership and leadership strategies are crucial in such development, and the effects of leadership on employee well-being are unquestionable (Kouppala et al., 2008). With regard to bullying, it has been found that ethical leadership is negatively associated with the occurrence of bullying (Stouten et al., 2010). However, other leadership styles and behaviours could also be relevant from a bullying prevention perspective. Further, targeting to reduce or even eliminate behaviours of knowledge hoarding between employees also holds the potential of improving trust and justice, which would influence the occurrence of negative acts over time.

From a repair perspective, focusing on just processes in dealing with cases of bullying may buffer the impact of the negative acts themselves. Cropanzano et al. (2007) suggested that, unrelated to any given change in outcome, a significant difference to the perception of a

\begin{tabular}{l|l|l} 
VOL. 20 NO. 22016 & JOURNAL OF KNOWLEDGE MANAGEMENT & PAGE 225
\end{tabular} 
situation can be brought about by the process being perceived as just. The evaluation of organizational justice is also based on employees' observations of what occurs to others (Rousseau, 2005), which suggests that injustice may be a factor related to negative reactions to bullying not only for targets but also for bystanders (Parzefall and Salin, 2010). Trust is also important in the repair process following the occurrence of bullying. It has been found that trust is both an essential element for the success of the resolution of bullying claims (Harrington et al., 2012) and a desired outcome of actually addressing workplace bullying (Pate et al., 2012). By demonstrating that negative acts have an impact on trust, justice, and knowledge hoarding beyond the individual level, the present study suggests that repair initiatives may potentially focus on intervening at the work unit level to improve the general social exchange quality within a given organization.

The findings of the present study underscore the importance of the developing field of research in behaviours of not sharing knowledge at work. While research has mainly focussed on knowledge sharing behaviours and business strategies to obtain that, knowing more about antecedents, processes, and outcomes of non-sharing behaviours holds the potential of bringing both strands further. The present study explicitly hypothesized about levels and referents of knowledge hoarding. Future research would benefit from further developing this line of thought by investigating the influence of differences and similarities in levels and referents between knowledge hiding and knowledge hoarding. For example, it could be of value to challenge the dyadic notion of knowledge hiding and explore whether knowledge hiding also occurs as a collective phenomenon, for example, between groups of employees. Research exploring the relation between knowledge hiding and hoarding would further add to the development of the field of knowledge management.

A direct, predictive relation between knowledge hoarding and negative acts was not supported by the present study. This finding does not, however, preclude that behaviours of not sharing information can lead directly to negative acts. It could indeed be posited that non-sharing behaviours with distinct source-recipient relations, as is the case with knowledge hiding, could predict the individual experience of negative behaviours over time directly. Investigating this particular relation would also constitute a valuable avenue for future research. Further, comparable to spill-over effects of breach in trust (Searle et al., 2011), witnessing negative acts directed towards others may also affect the quality of social exchange relations. For example, Parzefall and Salin (2010) suggested that bullying may contribute to bystanders' perceived organizational injustice and therefore produce effects beyond the specific relation between perpetrator and target. Therefore, investigating whether the effects on knowledge hoarding behaviours and experienced trust and justice differ for targets and bystanders of negative acts would contribute to the further advancement of the field.

\section{Acknowledgement}

This research was supported by The Danish Working Environment Research Fund under grant number 20050072524/4 and The Danish Council for Independent Research under grant number DFF-1319-00092. The authors wish to acknowledge Dr Bart de Jong for valuable feedback on the paper.

\section{References}

Alavi, M. and Leidner, D.E. (2001), "Review: knowledge management and knowledge management systems: conceptual foundations and research issues", MIS Quarterly, Vol. 25 No. 1, pp. 107-136.

Bies, R.J. and Tripp, T.M. (1996), "Beyond distrust:'Getting even' and the need for revenge", in Kramer, R. and Tyler, T.R. (Eds), Trust in Organizations: Frontiers of Theory and Research, Sage Publications, Thousand Oaks, CA, pp. 246-260.

Bijlsma, K. and Koopman, P. (2003), "Introduction: trust within organisations", Personnel Review, Vol. 32 No. 5, pp. 543-555.

Blau, P.M. (1964), Exchange and Power in Social Life, Wiley, New York, NY. 
Černe, M., Nerstad, C.G.L., Dysvik, A. and Škerlavaj, M. (2014), "What goes around comes around: knowledge hiding, perceived motivational climate, and creativity", Academy of Management Journal, Vol. 57 No. 1, pp. 172-192.

Cohen-Charash, Y. and Spector, P.E. (2001), "The role of justice in organizations: a meta-analysis", Organizational Behavior and Human Decision Processes, Vol. 86 No. 2, pp. 278-321.

Colquitt, J.A., LePine, J.A., Piccolo, R.F., Zapata, C.P. and Rich, B.L. (2012), "Explaining the justiceperformance relationship: trust as exchange deepener or trust as uncertainty reducer?", Journal of Applied Psychology, Vol. 97 No. 1, pp. 1-15.

Colquitt, J.A., Scott, B.A. and LePine, J.A. (2007), "Trust, trustworthiness, and trust propensity: a meta-analytic test of their unique relationships with risk taking and job performance.", Journal of Applied Psychology, Vol. 92 No. 4, pp. 909-927.

Colquitt, J.A., Scott, B.A., Rodell, J.B., Long, D.M., Zapata, C.P., Conlon, D.E. and Wesson, M.J. (2013), "Justice at the millennium, a decade later: a meta-analytic test of social exchange and affect-based perspectives.", Journal of Applied Psychology, Vol. 98 No. 2, pp. 199-236.

Connelly, C.E. and Zweig, D. (2015), "How perpetrators and targets construe knowledge hiding in organizations", European Journal of Work and Organizational Psychology, Vol. 24 No. 3, pp. 479-489.

Connelly, C.E., Zweig, D., Webster, J. and Trougakos, J.P. (2012), "Knowledge hiding in organizations", Journal of Organizational Behavior, Vol. 33 No. 1, pp. 64-88.

Cropanzano, R., Bowen, D.E. and Gilliland, S.W. (2007), "The management of organizational justice", The Academy of Management Perspectives, Vol. 21 No. 4, pp. 34-48.

Dietz, G. and Den Hartog, D. (2006), "Measuring trust inside organisations", Personnel Review, Vol. 35 No. 5, pp. 557-588.

Dirks, K.T. and Ferrin, D.L. (2001), "The role of trust in organizational settings", Organization Science, Vol. 12 No. 4, pp. 450-467.

Dyer, J.H. and Chu, W. (2000), "The determinants of trust in supplier-automaker relationships in the US, Japan, and Korea”, Journal of International Business Studies, Vol. 31 No. 2, pp. 259-285.

Einarsen, S., Hoel, H. and Notelaers, G. (2009), "Measuring exposure to bullying and harassment at work: validity, factor structure and psychometric properties of the Negative Acts Questionnaire-Revised", Work \& Stress, Vol. 23 No. 1, pp. 24-44.

Einarsen, S., Hoel, H., Zapf, D. and Cooper, C.L. (2011), "The concept of bullying and harassment at work: the European tradition", in Einarsen, S., Hoel, H., Zapf, D. and Cooper, C.L. ( Eds), Bullying and Harassment in the Workplace: Developments in Theory, Research, and Practice, Taylor \& Francis Group, Boca Raton, pp. 3-40.

Evans, J.M., Hendron, M.G. and Oldroyd, J.B. (2014), "Withholding the ace: the individual-and unit-level performance effects of self-reported and perceived knowledge hoarding", Organization Science, Vol. 26 No. 2, pp. 494-510.

Gillespie, N.A. and Mann, L. (2004), "Transformational leadership and shared values: the building blocks of trust", Journal of Managerial Psychology, Vol. 10 No. 6, pp. 588-607.

Hansen, Å.M., Hogh, A. and Persson, R. (2011), "Frequency of bullying at work, physiological response, and mental health", Journal of Psychosomatic Research, Vol. 70 No. 1, pp. 19-21.

Harrington, S., Rayner, C. and Warren, S. (2012), "Too hot to handle? Trust and human resource practitioners' implementation of anti-bullying policy", Human Resouce Management Journal, Vol. 22 No. 4, pp. 392-408.

Hauenstein, N.M., McGonigle, T. and Flinder, S.W. (2001), "A meta-analysis of the relationship between procedural justice and distributive justice: implications for justice research", Employee Responsibilities and Rights Journal, Vol. 13 No. 1, pp. 39-56.

Hislop, D. (2013), Knowledge Management in Organizations, Oxford University Press, Oxford.

Hodgins, M., MacCurtain, S. and Mannix-McNamara, P. (2014), "Workplace bullying and incivility: a systematic review of interventions", International Journal of Workplace Health Management, Vol. 7 No. 1, pp. 54-72.

Hoel, H., Sheehan, M.J., Cooper, C.L. and Einarsen, S. (2011), "Organisational effects of workplace bullying", in Einarsen, S., Hoel, H., Zapf, D. and Cooper, C.L. (Eds), Bullying and Harassment in the Workplace: Developments in Theory, Research, and Practice, Taylor \& Francis Group, Boca Raton, pp. 129-148. 
Hogh, A., Mikkelsen, E.G. and Hansen, A.M. (2011), "Individual consequences of workplace bullying/ mobbing", in Einarsen, S., Hoel, H., Zapf, D. and Cooper, C.L. (Eds), Bullying and Harassment in the Workplace: Developments in Theory, Research, and Practice, Taylor \& Francis Group, Boca Raton, pp. 107-129.

Homans, G. C. (1961), Social Behavior: Its Elementary Forms, Harcourt, Brace \& World, New York, NY.

Hsu, I.C. (2008), "Knowledge sharing practices as a facilitating factor for improving organizational performance through human capital: a preliminary test", Expert Systems with Applications, Vol. 35 No. 3, pp. 1316-1326.

Ismail Al-Alawi, A., Yousif Al-Marzooqi, N. and Fraidoon Mohammed, Y. (2007), "Organizational culture and knowledge sharing: critical success factors", Journal of Knowledge Management, Vol. 11 No. 2, pp. 22-42.

Jarvenpaa, S.L. and Majchrzak, A. (2008), "Knowledge collaboration among professionals protecting national security: role of transactive memories in ego-centered knowledge networks", Organization Science, Vol. 19 No. 2, pp. 260-276.

Jawahar, I.M. (2002), "A model of organizational justice and workplace aggression", Journal of Management, Vol. 28 No. 6, pp. 811-834.

Kim, W.C. and Mauborgne, R. (1998), "Procedual justice, strategic decision making, and the knowledge economy", Strategic Management Journal, Vol. 19 No. 4, pp. 323-338.

Kouppala, J., Lamminpää, A., Liira, J. and Vainio, H. (2008), "Leadership, job well-being, and health effects - a systematic review and meta-analysis", Journal of Occupational and Environmental Medicine, Vol. 50 No. 8, pp. 904-915.

Lambert, E.G., Hogan, N.L. and Griffin, M.L. (2007), "The impact of distributive and procedural justice on correctional staff job stress, job satisfaction, and organizational commitment", Journal of Criminal Justice, Vol. 35 No. 6, pp. 644-656.

Lavelle, J.J., Rupp, D.E. and Brockner, J. (2007), "Taking a multifoci approach to the study of justice, social exchange, and citizenship behavior: the target similarity model†", Journal of Management, Vol. 33 No. 6, pp. 841-866.

McEvily, B. and Tortoriello, M. (2011), "Measuring trust in organisational research: review and recommendations", Journal of Trust Research, Vol. 1 No. 1, pp. 23-63.

McKnight, D.H., Kacmar, C.J. and Choudhury, V. (2004), "Dispositional trust and distrust distinctions in predicting high-and low-risk internet expert advice site perceptions", E-Service, Vol. 3 No. 2, pp. 35-58.

Meadow, C.T. and Yuan, W. (1997), "Measuring the impact of information: defining the concepts", Information Processing \& Management, Vol. 33 No. 6, pp. 697-714.

Mikkelsen, E.G.E and Einarsen, S. (2002), "Basic assumptions and symptoms of post-traumatic stress among victims of bullying at work", European Journal of Work and Organizational Psychology, Vol. 11 No. 1, pp. 87-111.

Morrison, E.W. and Robinson, S.L. (1997), "When employees feel betrayed: a model of how psychological contract violation develops", Academy of Management Review, Vol. 22 No. 1, pp. 226-256.

Nielsen, M.B., Notelaers, G. and Einarsen, S. (2011), "Measuring exposure to workplace bullying", in Einarsen, S., Hoel, H., Zapf, D. and Cooper, C.L. (Eds), Bullying and Harassment in the Workplace: Developments in Theory, Research, and Practice, Taylor \& Francis Group, Boca Raton, pp. 149-174.

Parzefall, M.R. and Salin, D.M. (2010), "Perceptions of and reactions to workplace bullying: a social exchange perspective", Human Relations, Vol. 63 No. 6, pp. 761-780.

Pate, J., Morgan-Thomas, A. and Beaumont, P. (2012), "Trust restoration: an examination of senior managers' attempt to rebuild employee trust”, Human Resource Management Journal, Vol. 22 No. 2, pp. 148-164.

Peng, H. (2012), "Counterproductive work behaviors among Chinese knowledge workers", International Journal of Selection and Assessment, Vol. 20 No. 2, pp. 119-138.

Podsakoff, P.M., MacKenzie, S.B., Lee, J.Y. and Podsakoff, N.P. (2003), "Common method biases in behavioral research: a critical review of the literature and recommended remedies", Journal of Applied Psychology, Vol. 88 No. 5, p. 879-903. 
Quigley, N.R., Tesluk, P.E., Locke, E.A. and Bartol, K.M. (2007), "A multilevel investigation of the motivational mechanisms underlying knowledge sharing and performance", Organization Science, Vol. 18 No. 1, pp. 71-88.

Renzl, B. (2008), "Trust in management and knowledge sharing: the mediating effects of fear and knowledge documentation”, Omega, Vol. 36 No. 2, pp. 206-220.

Robinson, S.L. (1996), "Trust and breach of the psychological contract", Administrative Science Quarterly, Vol. 41 No. 4, pp. 574-599.

Robinson, S.L. (2008), "Dysfunctional workplace behavior", The Sage Handbook of Organizational Behavior, Vol. 1 No. 1, pp. 141-159.

Rousseau, D.M. (2005), I-deals, Idiosyncratic Deals Employees Bargain for Themselves, Routledge, New York, NY.

Rousseau, D.M., Sitkin, S.B., Burt, R.S. and Camerer, C. (1998), "Not so different after all: a cross-discipline view of trust", Academy of Management Review, Vol. 23 No. 3, pp. 393-404.

Salin, D. (2008), "The prevention of workplace bullying as a question of human resource management: measures adopted and underlying organizational factors", Scandinavian Journal of Management, Vol. 24 No. 3, pp. 221-231.

Searle, R., Weibel, A. and Den Hartog, D.N. (2011), "Employee trust in organizational contexts", International Review of Industrial and Organizational Psychology 2011, Vol. 26 No. 1, pp. 143-191.

Six, F. and Sorge, A. (2008), "Creating a high-trust organization: an exploration into organizational policies that stimulate interpersonal trust building", Journal of Management Studies, Vol. 45 No. 5, pp. 857-884.

Stapleton, L.M. (2013), "Multilevel structural equation modeling with complex sample data", in Hancock, G.R. and Mueller, R.O. (Eds), Structural Equation Modeling: A Second Course, Information Age Publishing, Charlotte, NC, pp. 521-562.

Stenmark, D. (2002), "Information vs. knowledge: the role of intranets in knowledge management", System Sciences, 2002, HICSS: Proceedings of the 35th Annual Hawaii International Conference on, IEEE, Hawaii, pp. 928-937.

Stouten, J., Bailien, E., Van den Broeck, A., Camps, J., De Witte, H. and Euwema, M. (2010), "Discouraging bullying: the role of ethical leadership and its effects on the work environment", Journal of Business Ethics, Vol. 95 No. 1, pp. 17-27.

St-Pierre, I. and Holmes, D. (2010), "The relationship between organizational justice and workplace aggression”, Journal of Advanced Nursing, Vol. 66 No. 5, pp. 1169-1182.

Szulanski, G. (1996), "Exploring internal stickiness: impediments to the transfer of best practice within the firm", Strategic Management Journal, Vol. 17 No. S2, pp. 27-43.

Tepper, B.J. (2000), "Consequences of abusive supervision", Academy of Management Journal, Vol. 43 No. 2, pp. 178-190.

Vartia, M. and Leka, S. (2011), "Interventions for the prevention and management of bullying at work", in Einarsen, S., Hoel, H., Zapf, D. and Cooper, C.L. (Eds), Bullying and Harassment in the Workplace: Developments in Theory, Research, and Practice, Taylor \& Francis Group, Boca Raton, pp. 107-129.

Walster, E., Berscheid, E. and Walster, G.W. (1973), "New directions in equity research.", Journal of Personality and Social Psychology, Vol. 25 No. 2, pp. 151-176.

Webster, J., Brown, G., Zweig, D., Connelly, C.E., Brodt, S. and Sitkin, S. (2008), "Beyond knowledge sharing: withholding knowledge at work", Research in Personnel and Human Resources Management, Vol. 27 No. 1, pp. 1-37.

Zhang, M.J. (2009), "IS support for knowledge management and firm performance: an empirical study", in Jennex, M.E. (Ed.), Management, Organizational Memory and Transfer Behavior: Global Approaches and Advancements, Information Science Reference, Hershey PA.

\section{Corresponding author}

Ann-Louise Holten can be contacted at: ann-louise.holten@psy.ku.dk

For instructions on how to order reprints of this article, please visit our website: www.emeraldgrouppublishing.com/licensing/reprints.htm

Or contact us for further details: permissions@emeraldinsight.com 